\title{
The rise of lifelong learning and fall of adult education in India
}

\author{
Sayantan Mandal* - National Institute of Educational Planning and \\ Administration, India
}

\begin{abstract}
This article focuses on the dynamic relationships between the growing importance of lifelong learning (LLL) and consequent devaluation of adult education in national level educational policies, plans and programmes in India. It argues that by adapting the new paradigm of LLL, which is largely driven by marketcentric neoliberal principles, Indian adult education has lost its core and traditional learning ecology as there is a gradual submission to the pursuit of global economic competitiveness. It identifies three main reasons for the submission: (1) the metamorphosis from welfare to market principles in reforming education; (2) blind acceptance and misunderstanding of LLL as an educational and not a political discourse; (3) fragmented reforms in revamping adult education in India in the last decades.
\end{abstract}

Keywords: India, lifelong learning, adult education, neoliberal educational reforms, marketcentric educational reforms, fall of adult education, decline of welfare policies, literacy in India, Indian adult education

\section{Introduction}

The history of learning is as old as the history of humankind, and in India, one of the oldest civilizations in the world, renowned for its culture and scholarship, the philosophy of lifelong learning (LLL) has long been a cherished goal (Dutta, 1986; Bhatia, 2009; Shah, 2009, 2010). In the post-Independence India (post-1947), LLL evolved as an integral and symbiotic part of adult and continuing education programmes woven into the fabric of nation-building and social transformation. However, the (re)advent of LLL in the post-millennium era has appeared in a different form. LLL is now perceived as a doctrine for development, to gain skills and remain employable throughout an individual's life. It is no longer limited to any specific field(s) and has appeared as an overarching principle that guides the trajectories of education policies towards economic growth (Field, 2006; Shah 2009, Barros, 2012). This notion is backboned by neoliberal ideologies and governed by market dynamics (Appadurai, 2001; Jarvis, 2008; Dixit, 2009; Mandal, 2015). This rechampioning of LLL has largely overshadowed traditional adult education (AE) in India, with which LLL was initially associated. Reduced funding, no new programmes and peripheral support from the government have evidently been reflecting the gradual devaluation of $A E$ in the national arena. Interestingly enough, $A E$ in India, through its established institutions, programmes, networks, conferences and courses, provided the initial platform and a springboard to LLL. 
This article therefore makes an attempt to discuss why the rise of LLL in India under neoliberal principles has devalued traditional AE, which initially vouched for LLL. Is it an evolution of AE into LLL or the beginning of a new paradigm? And what are the implications of this change on traditional AE in India.

The following section provides a brief recapitulation of $A E$ in India, and is followed by a discussion on how funding, focus and attention on AE in India rose in the 1970s and 1980s, then gradually reduced more recently. It shows how recent national policies are withdrawing support from welfare initiatives that used to fund AE much more substantially and why there is a gradual submission of $A E$ to the pursuit of global economic competitiveness. To critically analyse the issue, it elaborates three points. First, it seems important to examine the influence on Indian AE of the metamorphosis from welfare to marketcentric reforms in education. Secondly, we need to study how LLL became a dominant part of mainstream Indian education policies and the role of Indian academia in accepting it somewhat non critically. Coupled with this, the failures to revamp $A E$ through fragmented, short-lived reforms also accelerated the formation of a new LLL, which took a new shape that is largely divorced from the traditional notion of $A E$.

\section{Development of adult education in India}

It is difficult to trace the roots of AE in Indian history, as most of it was oral and there were substantial levels of variations and regional diversities. The following paragraphs are an effort to briefly present the development of AE in the context of India, based on the available scholarly works. The broad classification of timeframes is also depicted in the diagram (Figure 1), which is based on the studies of Dutta (1986) and Shah (1999) on the history of Indian education.

The diagram is divided into four major parts. The first part is LLL in ancient India and the second part extends up to the time when the British colonized India (LLL in the medieval period). The third part, LLL in the pre-Independence period, shows that the meaning of LLL was narrowed to adult learning. Importance was given to initiatives of $A E$ and learning along with other associated issues. The fourth part (LLL post-Independence) represents the development of AE until recent times. It ends by showing that the concept of AE has started to change once again, with LLL on the rise.

LLL has been an integral part of Indian culture since the ancient scripts (from 2000 BC to AD 1200) accorded prime importance to the virtues of learning (Shah, 2009, 2010; Mandal, 2013b). 'Learn as long as you live' to gain 'moksha' or emancipation (Shah, 1999) was rooted in a spiritual context, whereas learning exclusively for adults, or AE as we call it today, came much later.

During the Buddhist and Jain period, universities of international reputation were established in India. With the beginning of the medieval period, the Muslim system of education also paved its way to the subcontinent. Large numbers of maktabs and madrasas (Islamic schools) were established along with the existing pathsalas (schools) in almost every village (Acharya, 1989). This continued for a long time with the tradition of oral transmission of knowledge, values and culture. Most rulers extended considerable patronage to the scholars, and towards different forms of art and culture. The local temples became the places where the 3 Rs were imparted to adults through informal folk learning and interactions. However, a large section remained outside any organized education, as the temples were not accessible to many who belonged to the lower social strata (Mandal, 1993). 


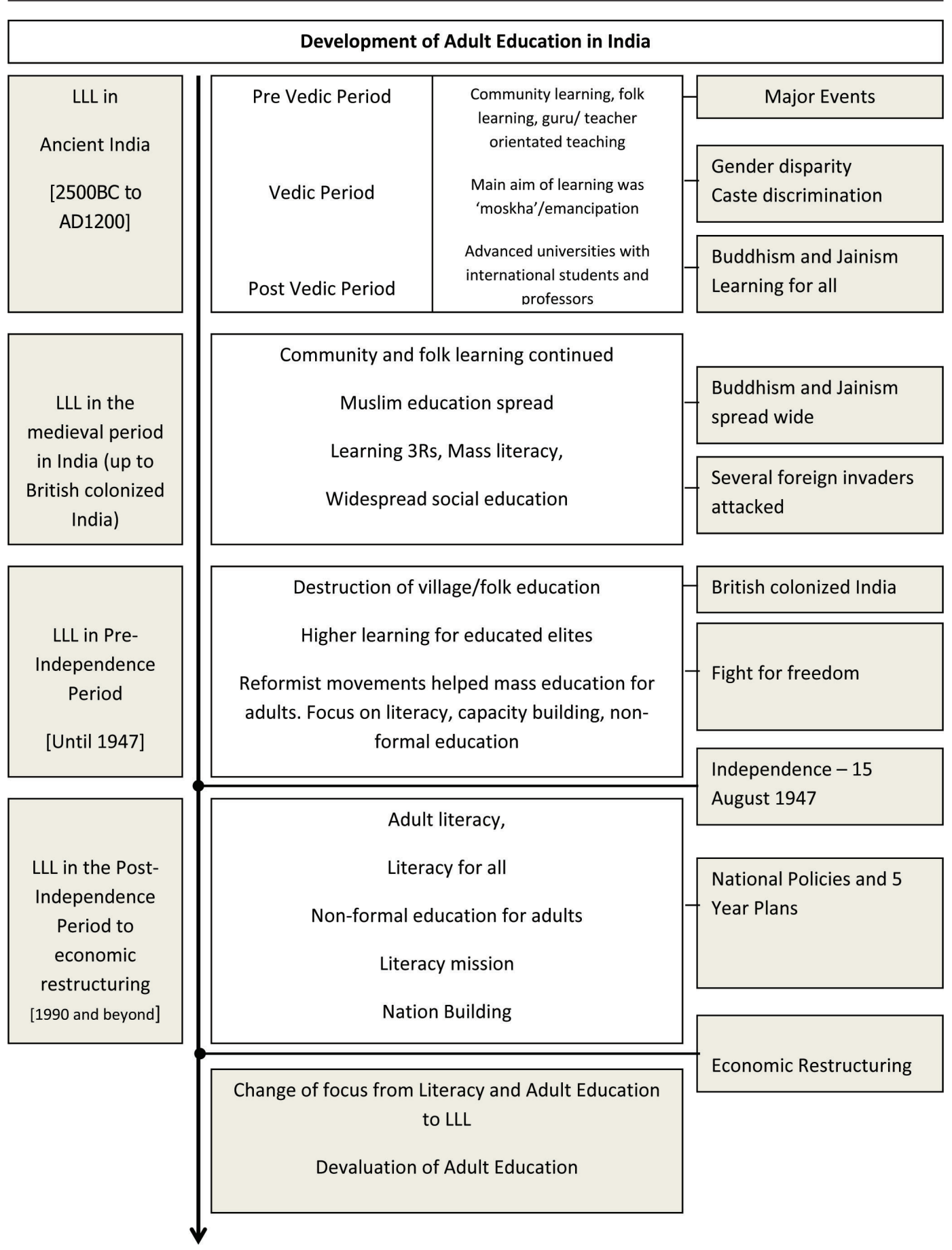

Figure 1: Development of adult education in India (after Shah, 1999; Dutta, 1986)

Later, during British rule, the country witnessed a total change in the social and administrative order. As analysed by Singh (1957), the colonizers' policy in India was to turn the country into a producer of raw materials for British industries, and as a consequence, education as a whole was neglected initially. Later, they started establishing primary schools and AE centres (Chatterjee, 1998, 2002) where the core curriculum included rudiments of reading, writing and deciphering. A number of nongovernmental organizations and social reform societies, many of which also worked as catalysts for the freedom movements, played a significant role in promoting $A E$ during the first quarter of the twentieth century. The period 1927-47 may be marked as 
a period of decline in adult learning, owing to the impact of a global economic crisis alongside political disturbances and communal riots in the Indian subcontinent.

India finally became free on 15 August 1947. In post-Independence India, AE was conceived as a robust instrument of nation-building that would improve basic literacy from a mere 18.33 per cent in 1951 (the first census of independent India), with a female literacy rate of only 8 per cent. It also helped to bridge societal inequality and discriminations, which were aggravated by economic inequalities and the poor education levels of the masses. India needed a ground-up plan for the formal as well as the non-formal sectors, especially for those who were outside the purview of formal schooling.

From 1947 to 1966 the focus of AE was on life-orientated education, with social education gaining priority in national policies (Shah, 1999). Social education was adopted as one of the flagship programmes of 'people's education' after Independence, with a greater emphasis on its social aspects and the innate objective of bringing desirable social change through widespread cooperation (Dutta, 1986). The movement for literacy in rural India (Gram Sikshan Mahim) spread, with the aim of improving the 3Rs, health and hygiene, principles and methods of cooperation, local arts and handicrafts, entertainment and general knowledge.

After initial efforts to improve basic literacy, the next phase (1967-77) attempted to take $A E$ to the next level. Several programmes were designed to impart functional literacy, and vocational training gained momentum in an effort to make India a selfreliant nation. The Farmers Functional Literacy Project, Non Formal Education and Functional Literacy for Adult Women were some of the successful programmes initiated during this period. The third cycle (1978-86) rechampioned social education, launching the Mass Programme of Functional Literacy, the National Adult Education Programme (NAEP) and other skills development programmes.

With a social welfarecentric vision, the government also invited Paulo Freire (in 1978) for his suggestions on spreading literacy, critical thinking and self-empowerment thorough the 'eclectic' method of teaching and learning (Mandal and Mandal, 2013). Freire's vision combined with the welfarecentric developmental approach of the government and increased investment made the NAEP a great success. Interestingly, the success of the programme narrowed down the concept of $A E$ and lifelong education largely to literacy and allied initiatives (Mandal, 2015). In the policies, plans and nomenclatures of AE organizations, literacy appeared as the prime mandate.

An exclusive emphasis on basic literacy, in spite of changing notions about functional literacy, civic literacy, development literacy and so forth, was reinforced further with the National Education Policy 1986 (revised in 1992) (MHRD, 1992), which put forward the agenda of economic reforms and limited AE to literacy and basic skill development activities for the economically and socially disadvantaged. The National Literacy Mission started in 1988, and continued to impart basic literacy with a renewed aim of universalization of elementary education for all.

The 1990s was a time of economic restructuring in India with the entry of neoliberal and marketcentric principles into the mainstream. This had a profound impact on the course of AE. From the early 1990s to 2000, national Five Year Plans observed that it was important to upgrade skills continuously to produce the manpower needed for a market and society (Government of India, 1992). Along with the government and non-governmental organizations, university departments of Adult Continuing Education and Extensions (ACEE) started to offer skills development programmes, but without proper attention on the development of teachers' and trainers' professional capabilities (Shah, 2009). 
In the post-2000 period, LLL entered into the mainstream policy lexicon when international policy bodies, such as the United Nations Education and Cultural Organization (UNESCO) and the European Commission, championed the idea with substantial differences in their approaches. However, the AE programmes in India did not witness any major shift until after 2010. During the Eleventh Plan period (2007-12) University Grants Commission (UGC) launched the Guideline on LLL and Extension, providing suggestions on how LLL could be promoted through ACEE university departments. This Guideline created a buzz at the time of its launch. Surprisingly, in 2013, within just a few years of launching the initiative, the UGC discontinued new funding for LLL. With replacement funding from the government not forthcoming, several programmes prematurely ended. Moreover, central funding to literacy programmes was initially reduced and then discontinued in 2018, without the launch of any replacements.

The funding of AE programmes was reduced gradually from the late 1980s and drastically after 2000. An analysis of funding patterns by Shah (2008) shows that while education expenditure to all sectors increased from 7.92 per cent to 13.78 per cent in 1951-98, in the case of AE expenditure declined from 5.30 to 0.31 per cent, further reducing to 0.26 per cent in the 2016/17 fiscal year. During the Sixth (1980-5), Seventh (1985-90) and Eighth (1992-7) plan period, the percentage of education outlay to the total plan for $A E$ was at an all-time high, at 5.07, 8.60 and 7.33 per cent respectively, after which it experienced a sharp decline (Shah, 2008). The contribution made by AE was 0.01 per cent of GDP, the lowest among all the educational sectors (Government of India, 2018a) making it the least productive sector to invest in, leading to even smaller budget allocations. In fact, budget expenditure on education departments on capital account for 2014/15 (actual) for AE combining all the states and union territories was nil, as per the analysis of Budget Expenditure on Education 2014/15 to 2016/17, published by the Ministry of Human Resource Development (Government of India, 2018: 12).

\section{The rise of $L L L$ and the fall of $A E$ in India}

While AE experienced budget cuts and lost its foothold in India from the 1990s, LLL appeared as a new policy area in the post-2000 period. This change may be clearly observed in the Tenth (2002-7) and Eleventh (2007-12) Five Year Plans of the Government of India (2002, 2007), which supported the marketcentric principles of learning and skills development above other objectives of formal and non-formal education. The National Knowledge Commission (2009) and the Yash Pal Committee Report to Rejuvenate Higher Education in India (2009), two major policy initiatives to revamp education, focused on the human resource development, using the contemporary and predominantly economistic principles of LLL. The Twelfth Five Year Plan (2012-17) does not mention LLL that often, but uses its principles in the document, indicating that LLL as a guiding principle is now rooted in the Indian national policy discourse.

The fund cuts and reduced importance of $A E$, on the one hand, and the increased importance of LLL, on the other, apparently seem to indicate the old making way for the new. However, as we shall discuss in the following subsections, AE and LLL in the Indian context have taken two different routes. Here it seems important to question why LLL is not an evolved form of AE in the Indian context. 


\section{Welfare to marketcentric education reforms and adult education in India}

In an effort to understand the complexities of the contemporary dimensions of LLL, from international to national levels, it is important to understand how the network between market and politico-economic powers have reshaped education in recent times (Appadurai, 2001; Jarvis, 2008; Field, 2006). It can be found that the dominant power in the global economy stems from those who control the economic and technological institutions (Jarvis, 2008: 20). Contrary to the Marxist theory that power lies within each society, Jarvis says that with globalization the formation of individual power structure has become a more complex and interconnected one. This mainly refers to the economic power spread across countries, consisting of private capital and multinational corporations, and often the political power of powerful nations, which puts substantial pressure on individual societies to conform to the dominating trend set by them. This 'sub-structure' (Jarvis, 2008) practises its power in each society through market mechanisms, opens up the possibility of exploring other markets, encourages big to grow bigger, helps to increase production and fosters innovation in order to meet the increasing demand of the global market. This also means that it encourages new learning, which can constantly invent, innovate and produce new commodities for the market. However, it mostly encourages certain kinds of scientific and other knowledge that are required for the growth of markets.

India, since its economic restructuring, has gradually entered into the new era of market economy. As a result, the education and allied policies of India have taken a path where the focus is not only on formal education, but also on all kinds of learning activities to make them compatible with the demands of globalization and the market. This clear shift from an earlier welfarecentric model demands technologically skilled people, managers, people who are self motivated to learn for their professional growth and not necessarily those with any knowledge (for example, a knowledge of poetry, unless this has a market value) that will allow them to administer businesses and invent new solutions to keep them thriving. The renewed focus of the national education policies is, in fact, not merely limited to business growth, and induces pressure from the substructure to produce more equipped and competent human resource for the domestic and global markets. The work of Rizvi and Lingard (2010) shows that this is not a unique phenomenon and can be witnessed worldwide; India is no exception.

In the midst of these changes, LLL has evolved as a powerful policy discourse, championed by transnational policy organizations such as the European Commission, UNESCO, the World Bank and the Organization for Economic Cooperation and Development. It is important to note that there are various and sometimes contradictory interpretations of LLL among these organizations and/or in the countries or regions they represent. However, analysing the new trends of LLL, it seems that unlike in the past, when LLL was considered as a path to achieve the zenith of knowledge and wisdom, the new form of LLL in major international policies is predominantly understood as a utilitarian way in which to promote human capital development. This egalitarian conceptualization of LLL has helped to redefine educational priorities by supporting what is defined as legitimate or useful, and reduced support to those forms of learning that are of less or no immediate economic value (Biesta, 2006).

With the change of terminology from education to learning, responsibilities have also been shifted to learners: everything now depends on their choice or willingness to learn depending on what is necessary for them to stay employed, become entrepreneurs or grow economically. On the one hand, this has helped the 
state to gradually withdraw its responsibilities as an educational provider for all, and on the other hand, individuals have become vulnerable to market forces, which now set learning agendas in nuanced economic terms. This commodification of education (Jarvis, 1995) has reinterpreted education in terms of productivity and competitiveness (Barros, 2012).

$A E$ in India, in its traditional form, was developed to focus on individuals and societies in a collective manner, where economic development was not among the prime objectives. However, with the renewed focus on fast economic growth, literacy initiatives for farmers, marginal workers, labourers in unorganized sectors, housewives and teaching semi-literates how to use banking services were no longer appealing. Investing in educational sectors with immediate economic returns or exploring the possibilities of marketing those educational sectors (such as higher education) soon became the prime policy direction. The word 'skills' became popular in public policy domains in India, to be succeeded by 'competences'.

In 2008, India launched the National Skill Development Corporation to impart skills and competence development through public-private partnerships; this opened the country's higher education sector to private universities and to the market at large. Today, nearly two-thirds (67.3 per cent; Government of India, 2018b) of enrolments are in private higher education institutions in India, most of them offering commercially viable courses. Deeply instrumental ideas of learning for earning or learning employability skills have been reinforced under the hegemonic concept of competences and LLL. Interestingly, India has not discarded its earlier notion of learning completely, and has continued with its traditional AE programmes. The reason for this lies at the heart of the democratic structure of the nation, and not in the market.

Indian democracy and political power directly depend on the voting rights of the majority, and no matter how influential the economic substructure may be, it cannot form a government that is able to intervene directly and openly. Political parties in India need the support of the people to gain and remain in power. To ease skyrocketing inequality, rising agitation and increasing unemployment, the political powers that be need to find solutions that appeal to the masses, in other words the majority of voters. By economic and social standards, the larger section of Indian population is still downtrodden; more than 70 years after Independence the nation still hosts the largest number of illiterates (nearly 230 million, or a third of the total) in the world. That is why, in addition to marketcentric policies, the political core has to continue with its populist welfarecentric policies for the educationally, socially and economically marginalized. Instead of all-out support for the substructure (full market control), national policies try to balance the situation, and these balancing acts create a kind of 'cushioning' effect (Habermas, 2006: 81 in Jarvis, 2008: 30), which claims to protect the deprived from the harsh competition promoted by the market. It also provides a buffer space to allow the gradual introduction of new dimensions of market control, which has the potential of gradually subsuming welfarecentric initiatives, including AE in its traditional guise.

\section{Acceptance of LLL in academia and as a policy initiative}

This section explains why accepting LLL non-critically and believing in its face value helped LLL to establish itself firmly in India, and to some extent defeat the original purposes of $A E$ in the process. While AE since the 1990s and especially in the early 2000s was losing its ground owing to decreasing funding, the internationally popular LLL appeared as a saviour, promoting the concept of 'learning from cradle to grave', similar to the ancient Indian philosophy of 'learn as long as you live'. However, the form 
of LLL that was championed by the West was more complex than the humble Indian philosophy of learning for enlightenment.

During the late 1990s and early 2000s international policy organizations, especially UNESCO and the European Commission, started to influence Indian policies with the evolving notion of LLL. The UNESCO (1996) report, 'Learning the Treasure Within', and the 'Memorandum of LLL' (2000) by the European Commission were the most influential documents in promoting the new notion of LLL. The guiding principles of lifelong education in order to form a learning society that had been promoted by the Faure document (Faure et al., 1972) created the ground for LLL to percolate swiftly through society by romanticizing (Jarvis, 1999) the virtues of learning. Later LLL mutated into a more agile tool to support the learning economy with modish repackaging of 'learning society'. Eventually, the social purpose and tradition in which AE thrived and supported the idea of a learning society was virtually replaced by the new concept of a 'learning economy' championed under LLL and allied policies. Over time, the UNESCO policies also started to support a more economically orientated dimension of LLL and became somewhat ambiguous (Jarvis, 2008) in nature.

Whereas UNESCO organized major conferences worldwide and in India (in Mumbai in 1998 and in Hyderabad in 2002) to promote LLL, the European Commission representatives and academics visited Indian universities and apex bodies, such as the UGC and the Association of Indian Universities, to promote Erasmus Mundus programmes, especially the European Masters in Lifelong Learning (MALLL) (Shah, 2018).

Several Indian students and professors received scholarships to study and teach in Europe. The European Union (EU) office in New Delhi recruited graduates from the MALLL cohort, the University of Delhi (DU) invited the former coordinator of the MALLL course as a visiting fellow, and the National Institute of Educational Planning and Administration (NIEPA) recruited faculty members with the MALLL degree. While the initiatives of the EU office in India, DU and NIEPA cannot be equated to changing the national policy perception of LLL, the European Commission initiatives, especially visits to India, partly influenced the adult educators of the Indian universities, the Indian Adult Education Association (IAEA) and the top officials of the UGC to bring out a document dedicated to LLL, for the first (and so far last) time. The UGC (2007) came up with a document called 'Guideline on Lifelong Learning'. This advocates bringing the LLL programmes 'in tune' with global knowledge scenarios, as LLL has become a fundamental goal of recent educational policies and is often advocated as a way to achieve socio-economic development and a tool for promoting the knowledge based society (ibid.: 3).

In parallel with the policy initiatives, major AE organizations in India began to hold conferences and seminars, and produce special journal issues, that used the term LLL. The IAEA and its subsidiary, the International Institute of Adult and Lifelong Education (IIALE), conducted their national conferences on the theme of LLL. The DU inaugurated the Institute of Lifelong Learning (ILLL) with a mission to transform educational and LLL curricula, content and capacity building for greater acceptance and practice of the ethos of LLL by the academic fraternity (ILLL website, DU). Several articles were published on or related to LLL, spreading the concept beyond the policy arena.

Support for LLL was growing, and in its public events LLL was adopted as the new direction that would revive Indian AE. Whereas these initiatives created a positive image of LLL, it perhaps neglected the lucid nature of it, which is widely discussed and debated in the West. The apparent 'noble' appearance of LLL was initially appealing, as it came with a promise to improve the educational as well as economic conditions 
of individuals, society and the market. In other words, it appeared to be an elixir for various problems and for multiple stakeholders. Biesta (2006) and Young (2000), however, raised concerns about the elusiveness of the term LLL. Its slipperiness (Barros, 2012) and composite nature give LLL its legitimacy, and also make it harder to question and counter it as a concept.

It did not take long before academia and officials directly associated with $\mathrm{AE}$ programmes began to recognize that AE could not be revived by promoting LLL alone. The author's personal interaction with the director of IIALE and other adult educators, and his participation in various meetings to discuss the future of AE in India, have revealed that the UGC 'Guideline on LLL' (2007) was hastily put together without proper empirical research into its applicability in the Indian context. Furthermore, there is a growing consensus that using LLL instead of AE has indirectly reduced the importance of $A E$ in India. The shift in government focus from welfarecentric $A E$ to employability skills and vocational training for young adults indicates that LLL is no longer confined within the domains of $A E$, which initially vouched for it. Instead, LLL has been conceived as an overarching framework, a guiding principle of educational policy formulation. AE has been left with meagre resources and even less attention.

\section{Fragmented initiatives to revive adult education in India}

This marginalization of Indian AE happened gradually, but was aggravated with the introduction of LLL. It happened partly because LLL was welcomed without a critical review or an analysis of its hidden nuances and nexuses; and partly because $A E$ embraced LLL as a means of its own revival, a strategy that backfired.

As a consequence, there are not one but multiple dimensions of LLL in India, each with its own specific and somewhat overlapping agendas, making the situation even more complex. The study of Mandal (2013a, 2013b, 2015) shows that the first dimension of LLL is related to the welfarecentric collective reforms, which, in its present guise, is mostly confined to the eradication of illiteracy. The second one is neoliberal in nature, where LLL is seen as a means which promotes the open market economy, privatization and individualized learning pathways. Here, LLL for economic growth is much in line with the internationally predominant perspective. There also exists a third type, termed the fragmented perspective, which tries to balance these two extreme perspectives (welfare and neoliberal). The efforts made by Indian academia to understand and promote LLL largely fall into the third category. This fragmented perspective allows LLL to be justified to all. The political angle clearly indicates that the benefit of economic globalization is being brought to India, and at the same time the traditional perspective of $L L L$ is being maintained in the form of $A E$, continuing education and so on. However, trying to be everywhere could also lead to a confused state where a lack of focus becomes evident.

The UGC 'Guideline on LLL' urged Departments of Adult and Continuing Education to change to Departments of LLL, and encouraged universities to introduce courses on LLL. DU, one of the largest and most prominent universities in India, launched the first fully-fledged Masters degree in LLL, the curriculum being similar to that of the European Masters in LLL (MALLL) that is taught in Denmark, the United Kingdom and Spain (2006-17). The Masters course in DU put a high priority on employability skills and recognized the instrumental values of learning. The UGC's attempt to change the names of departments and DU's efforts to design a curriculum that wasn't 'Indianized' indicate that the initiative was an academic afterthought in order to catch up with the 
new changes brought about by the internationally popular LLL. As a result, not many universities opted for the name change and DU is the only conventional Indian university to offer a full-time Masters programme for LLL. UGC has never again published a document exclusively dedicated to LLL. With nearly no academic positions advertised for departments of AE or LLL, and limited funding allocated to start new programmes, it is unlikely that other public universities will follow the path of the DU, unless forced to do so by the government.

This initial trend of going with the flow has nevertheless brought attention to Indian $A E$, such as international collaboration, faculty and student exchanges with European universities and establishment of international institutes in India. Sadly these initiatives are yet to revive AE in the country. Most of these efforts have embraced the dominant neoliberal perspective of LLL or are run in parallel with ongoing programmes, without much effort to make them complementary. In some cases, international collaboration has stopped (for example, the Asia-Europe Meeting network funding for LLL), or decreased (for example, DU's collaboration with a European university).

Owing to the paucity of funding or lack of adaptability to national realities, other programmes and efforts have reproduced documents and offered training programmes that are mostly repetitive and outdated, but have continued as long as the plan period fund allocation have supported them. In a recent letter to the Prime Minister of India, the IAEA (6 November 2018) said:

After Sakshar Bharat [Literate India] came to an end in March 2018, there is no adult education programme in the field. Institutions and individuals interested/ working in the field of adult and lifelong education eagerly waiting for the new policy and programme.

The letter continued by asking for support from the government to revive AE in India; and it is expected the new National Education Policy (NEP) will bring some significant changes in this regard. While the NEP has been a cherished goal of the present government since it came to power in 2014, and was re-elected in 2019, the first draft for discussion has been published only recently, in June 2019. The Draft NEP (MHRD, 2019) puts AE under 'Additional key focus areas' and mentions literacy, critical life skills, basic vocational skills, basic education, continuing education and digitalization as its priority areas. In the consultative meeting on the NEP 2019, organized by the IAEA (on 13 June 2019 in New Delhi), it was discussed that although the NEP proposes some changes, there is a lack of unique and 'exciting' programmes to revive AE (IAEA, 2019). According to the Draft NEP, AE programmes are to achieve their goals through voluntary initiatives, with the sketchy propositions of flexible funding raising questions about its plausibility.

It is perhaps important to note that after coming to power (in 2014), the government took a decision to discontinue the Five Year Plans, dissolved the Planning Commission of India and instead opted for a more flexible and marketcentric annual model to fund programmes. This direction of reform is unreservedly neoliberal. At this juncture, what the final NEP will bring for AE is unknown, but it is perhaps not difficult to foresee. Presently, the situation is bleak for traditional AE in India, and at a glance it is quite fragmented, without a robust strategy to revamp its lost glory. A closer examination shows that the traditional perspective of education is being questioned for its relevance today. It is being questioned from the pragmatic point of view that is situated in the present postmodernist context, coupled with neoliberal ideologies. 


\section{Towards a new beginning, or the end of an era?}

The trajectory of LLL in India is revolutionary in many ways, especially in the contemporary Indian context. However, the metamorphosis of LLL from AE to an overarching policy framework is not immune from criticisms. The dilemma of whether to keep the welfare perspective or the neoliberal one brings new challenges for Indian education policies and to their understanding of AE and LLL. After spending 40 years with a socialist pattern and a mixed economy (since Independence in 1947), there are new terms coming into play. These are liberalization, privatization, globalization and market friendliness (Kumar, 1998: 1391). LLL has become popular and powerful under the umbrella of neoliberalism, encompassing the above terms. In India, LLL has succeeded as a result of policy forethought, followed by a political afterthought that has been translated through academic support, which has made it almost immune from any strong resistance.

LLL today is perhaps best understood as a policy apparatus that is intentionally kept ambiguous (Biesta, 2006), so that different entities can define it in various ways depending on their agenda(s). This ambiguity is related to the political reconceptualization of LLL and not the philosophical conceptualization with which the traditional Indian AE has long been associated.

$A E$ in India was initiated by an effort to improve the educational and life conditions of adults, mostly outside formal schooling; thus, it is essentially a 'social transformation' plan, based on humanist ideology' (Barros, 2012: 130). But with the new notion of LLL, political mandates are pursued so that they are assimilated into all forms of education and learning, infused with neoliberal ideologies and backed by a powerful and extremely volatile market. The perception of LLL promoted by AE and by neoliberal policies thus stands at two extremes, with some apparent similarities on the surface. Moreover, these two LLLs are no longer contiguous and have taken two very different developmental routes.

It is therefore difficult to predict whether the new LLL will subsume traditional $A E$ or whether it will evolve independently, leaving $A E$ to find a roadmap of its own. Considering the circumstances, it can be concluded that no matter how powerful the new notion of LLL becomes, AE may not be entirely irrelevant in Indian society anytime soon. The burden of illiteracy, the power of voting democracy and the compulsion of populist strategies will keep AE alive in the peripheries. Whether this is desirable or not is a different debate, but it seems important that practitioners of $A E$, academia and policy think tanks understand the rhetoric of $L L L$ and its complex dimensions, which lie beyond its definitions, and start to question it from different vantage points.

\section{Notes on the contributors}

Sayantan Mandal is Assistant Professor at the National Institute of Educational Planning and Administration (NIEPA), India. He holds a PhD in Education Policy Analysis and graduated from the Danish School of Education, Copenhagen. Before joining NIEPA, he was a faculty graduate at the University of Delhi, intern at UNESCO (UIL, Hamburg) and has several years of working experience in the non-governmental organization sector, focusing on educational development of adults and neo-literates. 


\section{References}

Acharya, P. (1989) Bangla Desher Sikshachinta (in Bengali). Calcutta: Anustup.

Appadurai, A. (2001) 'Grassroots globalization and the research imagination'. In Appadurai, A. (ed.) Globalization. Durham, NC: Duke University Press, 1-21.

Barros, R. (2012) 'From lifelong education to lifelong learning: Discussion of some effects of today's neoliberal policies'. European Journal for Research on the Education and Learning of Adults, 3 (2), 119-34.

Bhatia, H. (2009) 'Lifelong learning: Changing perspectives'. In Chadha, N.K. (ed.) Readings in Lifelong Learning. New Delhi: University of Delhi, 66-85.

Biesta, G. (2006) 'What's the point of lifelong learning if lifelong learning has no point? On the democratic deficit of policies for lifelong learning'. European Educational Research Journal, 5 (3-4), 169-80.

Chatterjee, S. (1998) Rev. John Mark (The First Professor of Science in Modern India). Kolkata: Spark Publishing Concern.

Chatterjee, S. (2002) Dr. William Carey (in Bengali). Kolkata: Srerampore Press.

Dixit, V.K. (2009) 'Lifelong learning: Meaning, concept and perspective'. In Chadha, N.K. (ed.) Readings in Lifelong Learning. New Delhi: University of Delhi, 46-65.

Dutta, S.C. (1986) History of Adult Education in India. New Delhi: Indian Adult Education Association.

European Commission (2000) 'A Memorandum on Lifelong Learning'. Brussels: European Commission.

Faure, E., Herrera, F., Kaddoura, A.-R., Lopes, H., Petrovsky, A.V., Rahnema, M. and Champion Ward, F. (1972) Learning To Be: The world of education today and tomorrow. Paris: United Nations Educational, Scientific and Cultural Organization.

Field, J. (2006) Lifelong Learning and the New Educational Order. Rev. ed. Stoke-on-Trent: Trentham Books.

Government of India (1992) National Policy on Education 1986 (as modified in 1992). Ministry of Human Resource and Development. New Delhi: Government of India.

Government of India (2002) Tenth Five Year Plan - Education. New Delhi: Government of India.

Government of India (2007) Eleventh Five Year Plan - Education. New Delhi: Government of India.

Government of India (2018a) Analysis of Budget Expenditure on Education 2014-15 to 2016-17. Ministry of Human Resource and Development, Department of Higher Education. New Delhi: Government of India.

Government of India (2018b) All India Survey on Higher Education 2017-18. Ministry of Human Resource and Development, Department of Higher Education. New Delhi: Government of India.

Habermas, J. (2006) Time of Transitions. Ed. and trans. Cronin, C. and Pensky, M. Cambridge: Polity Press.

IAEA (Indian Adult Education Association) (2018) Letter to the Prime Minister on Adult Education Programmes- Support and Increased Funding- reg. dated 6 November 2018; F. no. IAEA/Adm/ 5-13-1/2017-19, New Delhi. IAEA.

IAEA (Indian Adult Education Association) (2019) Discussion on the Draft of the New Education Policy, focusing Adult Education. Dated 13 June 2019. India International Centre, New Delhi, IAEA.

Jarvis, P. (1995) Adult and Continuing Education: Theory and practice. 2nd ed. London: Routledge.

Jarvis, P. (1999) 'Global trends in lifelong learning and the response of the universities'. Comparative Education, 35 (2), 249-57.

Jarvis, P. (2008) Democracy, Lifelong Learning and the Learning Society: Active citizenship in a late modern age. London: Routledge.

Kumar, K. (1998) 'Education and society in post-independence India: Looking towards the future'. Economic and Political Weekly, 33 (23), 1391-6.

Mandal, S. (1993) Gana Saksharata: Dharana O Rupayan (in Bengali). Kolkata: National Book Agency.

Mandal, S. (2013a) 'Renewing Dimensions of Lifelong Learning in India and Its Consequences on the Contemporary National Higher Education Policies: A socio economic analysis in the age of globalization'. Unpublished PhD thesis, University of Deusto, Bilbao.

Mandal, S. (2013b) 'From policy to guidelines: Metamorphosis of lifelong learning in India'. International Journal of Lifelong Education, 32 (2), 190-208 . 
Mandal, S. (2015) 'Learning the world? Changing dimensions of adult education and lifelong learning in India'. In Milana, M. and Nesbit, T. (eds) Global Perspectives on Adult Education and Learning Policy. Basingstoke: Palgrave Macmillan, 148-62.

Mandal, S. and Mandal, S. (2013) Paulo Freire: Jibon O Sikshadarshan (Paulo Freire: Life and Educational Philosophy - in Bengali). Kolkata: Indian Paulo Freire Institute.

MHRD (Ministry of Human Resource Development) (1992) National Policy on Education 1986 (as modified in 1992). New Delhi: Government of India.

MHRD (Ministry of Human Resource Development) (2018a) All India Survey on Higher Education 2017-18. New Delhi: Government of India.

MHRD (Ministry of Human Resource Development) (2018b) Analysis of Budgeted Expenditure on Education 2014-15 to 2016-17. New Delhi: Government of India.

MHRD (Ministry of Human Resource Development) (2019) Draft National Education Policy 2019. New Delhi: Government of India.

National Knowledge Commission (2009) Report to the Nation 2006-2009. New Delhi: National Knowledge Commission.

Rizvi, F. and Lingard, B. (2010) Globalizing Education Policy. London: Routledge.

Shah, S.Y. (1999) An Encyclopedia of Indian Adult Education. New Delhi: National Literacy Mission.

Shah, S.Y. (2008) Funding Adult Education Programmes in India: A study of policy, process, patterns and problems (Paulo Freire Memorial Lecture, 18-19 September). New Delhi: IAEA.

Shah, S.Y. (2009) 'Lifelong learning in India - opportunities and challenges'. Indian Journal of Adult Education, 70 (1), 15-39.

Shah, S.Y. (2010) 'Teaching and training in adult and lifelong learning in India: Need for professionalisation'. Indian Journal of Adult Education, 71 (4), 80-100.

Shah, S.Y. (2018) 'Lifelong learning in India: A policy perspective'. ASEM Education and Research Hub for Lifelong Learning. Online. https://tinyurl.com/y3u4dngw (accessed 13 August 2019).

Singh, S. (1957) History of Adult Education during British Period. New Delhi: Indian Adult Education Association.

UGC (University Grants Commission) (2007) Guidelines on Lifelong Learning and Extension. New Delhi: University Grants Commission.

UNESCO (United Nations Educational, Scientific and Cultural Organization) (1996) Learning: The treasure within. Paris: UNESCO Publishing.

UNESCO (United Nations Educational, Scientific and Cultural Organization) (1998) The Mumbai Statement on Lifelong Learning, Active Citizenship and the Reform of Higher Education. Hamburg: UNESCO.

UNESCO (United Nations Educational, Scientific and Cultural Organization) (2002) The Hyderabad Statement on Adult and Lifelong Learning. Hamburg: UNESCO.

UNESCO Institute for Education (1998) The Mumbai Statement on Lifelong Learning, Active Citizenship and the Reform of Higher Education. Hamburg: UNESCO Institute for Education.

Yash Pal Committee (2009) Report of the Committee to Advise on Renovation and Rejuvenation of Higher Education. New Delhi: Government of India.

Young, M. (2000) 'Bringing knowledge back in: Towards a curriculum for lifelong learning'. In Hodgson, A. (ed.) Policies, Politics and the Future of Lifelong Learning. London: Kogan Page, 97-110. 